\title{
International Society of Philosophy and Cosmology: Fifteen-Year History and Modernity
}

\author{
Denys Svyrydenko
}

\author{
Doctor of Philosophical Sciences, Associate Professor, Guangdong University of \\ Petrochemical Technology (Maoming, China) \\ E-mail: denis_sviridenko@ukr.net \\ https://orcid.org/0000-0001-6126-1747
}

\section{Hleb Khomenko}

Junior Research Fellow, Ph.D. Student, National Pedagogical Dragomanov University (Kyiv, Ukraine)

E-mail: homenkoglib@gmail.com

https://orcid.org/0000-0003-2897-5400

This article is an attempt to summarize the obtaining of the International Society of Philosophy and Cosmology (ISPC) activities for the fifteen years since its inception. This conceptualization attempt seems to be deliberate, given the considerable academic and societal demand for space exploration and popularization. The article demonstrates the institutional evolution of the International Society of Philosophy and Cosmology from the initiative of a small group of scientists to the level of a serious research society, prominently presented in the global science, and the one that brings together the efforts of active researchers from dozens of countries. The article is aimed at distinguishing the history of formation and summarizing the achievements of the International Society of Philosophy and Cosmology in a number of areas: space research, educational and political studies. Although the authors singled out these areas, each of them having a number of specific achievements, however, a mission, around which the activities of the International Society of Philosophy and Cosmology unfold, unites them all.

Keywords: International Society of Philosophy and Cosmology, philosophy, cosmology, space studies, political studies, educational studies, space travels, Bazaluk

Received: March 11, 2019; accepted: September 1, 2019

Philosophy and Cosmology, Volume 23, 2019: 178-187.

https://doi.org/10.29202/phil-cosm/23/17

(C) Svyrydenko, Denys, 2019

(C) Khomenko, Hleb, 2019 


\section{Introduction}

The study of the laws of the outer space functioning in its vast prospect has been of interest for the humankind since the emergence of Homo Sapiens as a species. The results of the first attempts of traditional societies to learn the nature of the universe, as well as their place in it, formed the basis for the formation of a number of mythological systems and religious beliefs. Such ideas have been passed down from generation to generation as an important spiritual value, without the perception of which people were doomed to live with a sense of uncertainty in an environment of the Universe completely unclear to them. Later, in the Antiquity, the desire to understand certain regularities of the universe led to the formation of the first philosophical ideas that were born in the minds of the most inquisitive figures of the time due to the long-term contemplation of the various phenomena of nature. More than two and a half thousand years have passed, the methodology of philosophical analysis has undergone significant changes, but the desire of a human to explore the nature of the cosmos has not disappeared, becoming one of the priority directions of the development of modern scientific knowledge.

In the last century, the great social excitement around space exploration was underpinned by socio-political factors - the USSR and US's efforts to expand their sphere of influence through the launching of satellites into orbit, the competition for superiority in the development of planets. Today, the space science as a scientific and a popular science problem is interesting to both researchers and ordinary citizens, giving the opportunity to learn more about the evolution and structure of the Universe. Undoubtedly, seeing the cosmos for the first time, one acquires a unique experience that forever changes one's personal worldview, and the problems of space exploration accordingly unfold in the scientific discourse of various fields. Because of this, space exploration is an object of scientific interest not only for physicists and astronomers, but also for scientists in a range of industries, from philosophers, space law researchers to psychologists and green space technology researchers.

Today, for 15 years now, the International Society of Philosophy and Cosmology (hereinafter referred to as ISPC) has been actively involved in these activities under the direction of Oleg Bazaluk, Ukrainian philosopher, the author of the philosophical model of the Universe "Evolutionary Matter." It is worth noting that the head of this association is the author of about two dozen monographs featuring brain development in the conditions of the Earth and outer space. The main area of his research is the philosophy of space. However, his research on space philosophy is projected on neurophilosophy, philosophy of education and political science.

The ISPC coordinates the consolidation processes within the philosophical and interdisciplinary studies of the cosmos, thus forming a unified association of scientists whose members pursue a common goal — the formation of a new image of a human with a planetary-space strategic worldview. The leading role in the transformation of the usual world outlook should be played by education, which is capable of helping people to discover the meaning of their own existence and the individual role that is assigned to everyone since their birth. Realizing their mission in this life, a person is able to break free from the routine of everyday life and to achieve a dreamy harmony with the universe. As a well-known institution in Ukraine and beyond, the ISPC is indebted to a number of domestic and foreign philosophers who have not been indifferent to the fate of philosophical space exploration. Gennadii Aliaiev, Georgy Gladyshev, Galina Zheleznyak, Serhiy Krychevsky, Akop Nazaretyan, Viktor Okorokov, Sergiy Rudenko, Denis Sviridenko, Arkady Ursul, Oleg Khoma, Olga Shkira figure prominently among these researchers. 
Any person can and should be a citizen of their country, but modern globalization trends require them to be able to think on a cosmic scale. The inability to adapt to such a trend threatens the future existence of society in peace and harmony with the environment, becoming a catalyst for the accumulation of various interpersonal misunderstandings. The activities of the International Society of Philosophy and Cosmology occupy a leading position in this process, which is aimed at preparing a person to perceive themselves as subjects not only of the earth but also of the outer space.

\section{International Society of Philosophy and Cosmology: From Researchers Initiative to International Research Area}

First, it should be emphasized that this international organization, on a voluntary basis, brings together scientists from different continents of the world, who are interested in the research into the interaction of a human, society and space. The history of functioning of this scientific society dates back to October 7, 2004, when upon the initiative of the participants of the 1st International Seminar "The Universe - Structure, Stages of Formation and Development" (October 5-7, 2004, Pereyaslav-Khmelnitsky, Ukraine) there was made a decision to establish the International Society of Philosophy and Cosmology. From the first day of its existence to this day, this society is open to philosophers and representatives of other fields of science, who are not indifferent to the fate of humankind in the near future. The members of the society are the leading theorists and practitioners from different countries of the world: Ukraine, Poland, Georgia, Germany, Netherlands, Japan, USA, Brazil, Greece, Spain, Canada, etc., who work on researching human development in the Universe.

The representative status of the society allows you to speak about its current high international status. All its members are highly active as authors of publications in journals published by the organization, participate in conferences organized by it, review manuscripts and represent the activities of the society in the international scientific and educational environment. In order to more systematically represent the achievements and outline the perspectives of ISPC's activities, the authors propose to concentrate on considering specific areas of its activities. With some degree of conventionality, there have been identified three key areas, which include space, educational and political studies. At the same time, these directions, in their entirety, make it possible to successfully accomplish the ISPC mission.

\section{Space Studies at the International Society of Philosophy and Cosmology}

The main direction of scientific and philosophical research of the International Society of Philosophy and Cosmology is devoted to the improvement of theories of the universe evolution, as well as the development of the theory of noogenesis, or the development of a human (intelligent matter - the term of Oleg Bazaluk) in the Universe. Oleg Bazaluk, the President of the International Society of Philosophy and Cosmology, is the head of this direction. According to the organizers and members of the ISPC, cosmological models, as well as synthetic theory of evolution, developed by scientific disciplines, are fully disclosed in the philosophy of space (cosmology). The philosophy of space creates the basis for combining cosmological models with synthetic theory of evolution, as well as for the creation of noogenesis theory, which considers the natural ascent of man in certain physical, chemical and biological conditions of material object [Bazaluk \& Kharchenko, 2018]. 
The interest in philosophical studies of space is growing not only among cohorts of scientists, but also among ordinary citizens, who want to know about the world in which they live more than it is written in textbooks. There is a powerful social demand for further comprehension of the Universe by humanity. Admittedly, more and more opportunities arise to fulfill this desire. In the 21st century, private companies are ready to offer space travel to anyone who can spend dozens of millions of dollars on it [Bazaluk, 2012]. Although an average person is not yet able to use the services of space tourism, since the end of the last century a human still dared to risk his own life to look at the Earth from the window of a spacecraft. Unfortunately, the first attempt of space tourism in 1986 proved fatal for an American teacher who was unprepared for such a test, both physically and possibly psychologically. However, it is quite symbolic that this innovative status was assigned precisely to the educational worker, and the educational issue in the ISPC's activities is a separate research area, which will be discussed in more detail in the next part of the article.

The first successful imprint in the history of the emergence of space tourism was made by American multimillionaire businessperson Dennis Tito, who went on a trip with professional astronauts. It is evident that all outsiders of the space programs had enormous amount of money, which allowed each to spend $\$ 30$ million on a single trip that lasted an average of about a week. After the tragic incident with an American teacher, professional astronauts accompanied each of the millionaire space tourists from Russia and the United States. You can argue about what exactly forced these people to such a risk - a thirst for knowledge or a desire to be even more recognized, perpetuating their name in the world history of space exploration. Nevertheless, each of them has made their own contribution to the promotion of space travel. The contribution of astronauts Leonid Kadeniuk and Sergiy Krychevsky, worldrenowned space exploration practitioners, who provided theoretical and practical research to the ISPC researchers, is invaluable within the ISPC's activities.

Given that the development of space tourism is only gaining momentum, it is necessary to give this phenomenon a more accurate scientific and philosophical justification. The ISPC also made an active contribution to the theoretical solution of space tourism, which hosted a conference in 2010 and published a collection of conference materials on relevant topics - Space Travel: Science, Education, Practice [Space Travel, 2010]. About twenty scientists, representatives of different institutions of national and international variety shared their scientific developments. The conference was held at the international level, given the excitement surrounding the issue and the need for its scientific interpretations. It was held on December 2, 2010 at Kyiv University of Tourism, Economics and Law. The conference was organized by the International Center for Space Law as a structural unit of the Institute of State and Law named after V. M. Koretskiy of NAS of Ukraine, International Society of Philosophy and Cosmology, National Space Agency of Ukraine, Kharkiv Planetarium named after Yu. A. Gagarin, Kyiv University of Tourism, Economics and Law, as well as other scientific organizations and public societies. Leonid Kadeniuk (1951-2018) was the guest of honor at the conference, the first and the only astronaut of independent Ukraine, Hero of Ukraine.

Two years later, thanks to the coordinated activities of the International Society of Philosophy and Cosmology, the world saw the almanac "Cosmic Ukraine. Pereyaslav region," which is aimed at a wide range of readers [Cosmic Ukraine, 2012]. The author of this educational project was the head of the ISPC and the director of the library of Pereyaslav-Khmelnitsky Pedagogical University, Honoured Worker of Culture of Ukraine Olga Shkira. Leonid Kadeniuk became the chairperson of the editorial board. In general terms, the popular science publication is dedicated to the promotion of outer space studies among young people. The 
publication presented a unique research material that comprehensively covers the scientific and educational role of Pereyaslav citizens, creative assets of students, graduate students and teaching staff in the context of the development of Ukraine as a cosmic state.

In 2012, with the assistance of the Society of Philosophy and Cosmology, the $14^{\text {th }}$ International Youth Scientific and Practical Conference "Man and Space" was held, which is a traditional scientific and educational platform for the exchange of original thoughts as well as innovative concepts within the given international community. It should be noted that this conference has been successfully held for a long period of time, and on April 10-12, 2019, the $21^{\text {st }}$ scientific conference was held under the auspices of the ISPC. Given that today the space industry of Ukraine and Europe in general really needs highly qualified scientific support and staffing, holding this conference is considered the best way to activate the younger generation in the direction of their scientific research.

Once again, the "Man and Space" conference provides a unique opportunity for students, graduate students, and young scientists to focus carefully on the subject, share experiences among their peers, and project the further development of their state's space industry. Outer space, as already stated, can unite scientists from different fields, and its research equally requires the proficient opinion of experts in the field of humanities and sciences, the application of philosophical approaches in the development of technical products, taking into account the peculiarities of the psyche of an individual. Quite fundamental in the context of the analysis of the interaction between the human's personal factor and outer space is the scientific work "Space Travels — Traveling Mentality". It was written by Oleg Bazaluk, based on current research in the fields of philosophy, neurophysiology, psychology and space medicine [Bazaluk, 2012].

In this work, the scientific and philosophical way of perceiving the outside world is nontrivially defined, as well as the fundamental principles of the existence of the world are substantiated. The author argues the hypothesis of cosmic ideology, according to which the cosmos exerts a direct influence on the order of mankind's existence throughout its period of development. His authorial model "Evolutionary Matter" is considered as the basis of modern theory of development of the Universe. The result of various transformations at the current stage of evolution should be the formation of planetary-space-type personality with a sense of significance on the planet Earth. In addition, this paper deals with such fundamental phenomena as the study of the embryonic development of a baby and childbirth in space flight, as well as the analysis of existing precedents related to the same problem. The content of this work, as well as all other important scientific achievements, can be found on the official website of the ISPC (http://en.bazaluk.org/).

During its existence, the ISPC has sought to develop a research component and reach an international level of research and academic cooperation. Promising in this regard, the members and management of the ISPC considered the creation of scientific journals to serve as a discussion platform for the publication of research results, for the development of professional communication with foreign authors. In the domain of philosophical and cosmological research, the steady development of "Philosophy and Cosmology" journal has allowed it to evolve from special issues of the Ukrainian scientific publication "Sententiae" to the level of a qualitative international scientific publication (http://ispcjournal.org/). A special marker of recognition of the publication quality was its inclusion in international citation database of research literature Web of Science in 2015.

A separate area of interest for the ISPC space research and a wide range of researchers is space law, whose current issues are discussed in "Advanced Space Law" journal, which 
has been published by the ISPC since 2018 (http://asljournal.org/). Space law research can be achieved through close collaboration with the Scientific Institute of Public Law (Kyiv, Ukraine). The director of this institute Valentin Galunko coordinates research in the field of space law and is the editor-in-chief of the scientific journal "Advanced Space Law." The main purpose of this journal is to facilitate the exchange of ideas and the development of collaboration with foreign scientists in the field of space law, as well as with the researchers of the legal aspects of space exploration.

In addition to the regular holding of scientific conferences on the interaction of man, society and space by the members of the ISPC, as well as their consistent work on the publication of collective monographs ("Space Travels", "Future Human Image: Who to Raise and How to Educate Adolescents"), the ISPC has repeatedly held working meetings, interviewed such prominent personalities as, mentioned in this article, Leonid Kadeniuk (2012), multiple Olympic Games champion, Hero of Ukraine Olena Yurkovskaya (2012), Ukrainian astronomer, pioneer of comets discoveries Klim Churyumov (2015) and others.

In particular, Leonid Kadeniuk expressed his own understanding of the image of the future human in a discourse with the chairperson of the ISPC. In his opinion, the future man is first and foremost an educated person. The criterion of their education is not only a certain educational degree, but also the ability to operate the opportunities of digital technologies, to navigate in the environment of changing trends of everyday reality. In the process of educating future generations, it should be borne in mind that the world is changing rapidly enough, and therefore education should be proactive, not the other way around. It is also important to instill an individual's ability to remain optimistic in all circumstances. This trait is characteristic of the American upbringing system. In addition to purposefulness and hard work, every progressive person must be prepared to exist in the face of huge flows of information, and therefore to distinguish the primary from the secondary, aiming at the genesis of humanity and "inspired" by modern media [Bazaluk, 2014].

According to Elena Yurkovskaya, man of the future is, first and foremost, a successful person. Success means the inoculation of as many positive qualities as possible, which will contribute to the full self-realization of an individual. Young generations should be educated in such a way that they can continue to live on the principles of goodness and responsiveness. These are the feelings that must be possessed by individuals with developed moral and willed qualities. If humiliation is considered to be the prerogative of morally immature people, kindness is a pivotal characteristic of a strong personality [Bazaluk, 2014].

In both interpretations of the image of the future man, it is stated that an innovative personality must be formed through effective methods of education and upbringing in the educational environment. If science seeks to develop qualitatively new knowledge of the world, thereby making a person's life more fulfilling, then education should socialize the subject, instill the habit of lifelong learning, and help realize their personal potential. The development of educational issues, which resonates with the mission of the ISPC, is devoted to a separate direction, headed by Denys Svyrydenko.

\section{Educational Studies at the International Society of Philosophy and Cosmology}

Denis Svyrydenko, professor at the National Pedagogical Dragomanov University, the flagship of national pedagogical education, heads this direction. In addition, within the scientific society, a modern educational center is successfully functioning, the development of which is honored by an honorary member of ISPC, Professor of Taras Shevchenko National 
University of Kyiv, Sergii Rudenko. The work of the center is based on advanced educational and methodological developments in the study of foreign languages, the formation of academic and management skills. Its services will be interesting and useful for all entrants who wish to study in Ukraine and other universities in Europe, educational staff, academics, businesspersons, government officials and NGO activists.

Unlike other educational platforms of Ukraine, the staff of this educational center successfully provides each participant not only with a wealth of knowledge, but also promotes the development of critical thinking, project-oriented style of thinking and actions that are especially necessary for each person in the period of large-scale socio-economic transformations, Industry 4.0 challenges. Moreover, the Educational Center of the International Society of Philosophy and Cosmology enables its students to consolidate all the skills acquired during their internships at the leading universities in Europe. As a result, each participant gets, first and foremost, the ability to navigate more effectively in perspective directions of activity and to build their own further professional trajectory of development according to current requests of the 21 st century.

In order to find effective educational strategies for shaping the modern and future-oriented development of humanity, the ISPC has launched the scientific journal "Future Human Image" (http://www.fhijournal.org/). The journal in its current state is the result of continuous improvement, published at the beginning of its formation once a year and mainly in Ukrainian and Russian, and since 2018, the journal has been published exclusively in English twice a year. The authors are well-known researchers from the USA, the Netherlands, Poland, Serbia, Turkey, China, India, South Africa, etc. Maintaining education at the center of the research scope, it contains publications of the results of modern research in the fields of philosophy, cultural studies, social sciences, law and public administration, which are devoted to futuristic issues. According to the editorial board of the journal, multidisciplinary is capable of finding an authentic image of man in the future culture, education, society, politics, technology, etc.

The activities of the members of the International Society of Philosophy and Cosmology in the educational domain are not limited to publishing activities and the provision of modern educational services. Within this community, there is a thorough research and educational activity, development of international projects, the leading of which is "Future Human Image." The main objective of this project is to conceptualize the latest educational paradigm, which will take the development of modern education as such to a new, higher level. Based on the unique psychic traits of modern generations of young people accustomed to the perception of the universe in the context of the ratio of the categories of information society, education, accordingly, should be oriented to the formation of an image of innovative personality that can coexist harmoniously with the surrounding world. Undoubtedly, harmonious coexistence of a person requires their complete self-realization, which will allow them to be located in the center of the society, not on its periphery, becoming a kind of passionator, the driving force of progress, but not vice versa - to be transformed into a carrier of marginal values and social values. These ideas are not only the subject of academic discussion, but are also spread in the circles of student youth, seeking to involve it in the study of space and human development prospects.

According to the ISPC organizer and head Oleg Bazaluk, modern society is in a state of ambivalent uncertainty. On the one hand, man of the third millennium finally departs from the worldview canons laid down by the spiritual heritage of the Enlightenment. On the other hand, the education systems in many countries - France, Germany, the USA, Ukraine and 
others - preserve "true" dominant pedagogical principles of the Age of Enlightens. For four centuries, a large number of generations of young people have been educated in schools and universities on the basis of recognizing the "crucial role of science and intellect in cognition", "the need to disseminate knowledge and educational culture." The organizers of the project "Future Human Image" appropriately took into account the severity of this problem and that is why they are trying to investigate the ambiguous nature of the impact of social institutions on youth mentality.

Collective work of internationally renowned scholars in the fields of philosophy, psychology, pedagogy, neuroscience, which has been tested in the framework of many scientific events, including several International scientific and practical Internet conferences "Future Human Image: Whom and How should We Educate in the Rising Generations" has been dedicated to resolving these contradictions in the dialogue between man and society [Future Human Image, 2011; Future Human Image, 2012; Future Human Image, 2013]. The conference materials that formed the basis for the publication of several volumes of collective monographs are available to the public on the official website of the International Society of Philosophy and Cosmology in the section of the Scientific Library (http://www.bazaluk.com/ scientific-library.html\#\%D0\%9E). By the way, the presence of two modern online libraries that are regularly updated, as well as reputable scientific developments - from articles to monographs by domestic and foreign authors - are also a hallmark of this scientific society.

In addition, through the development of existing contacts, the ISPC seeks to develop international cooperation and build prospects for international projects. Last year, an ISPC delegation led by the ISPC Vice President Denys Svyrydenko visited Palacky University, located in Olomouc. This working visit was aimed at intensifying the research cooperation between the ISPC and the Czech universities, as well as the participation of the members of the society in the training program "Practical Procedures and Problems of Creation and Innovation in ECTS Curriculum." We can assume that due to the effective establishment of external relations with universities in Europe and Asia, more publications published by scientists from the Czech Republic, Slovakia, Poland and China will appear on the pages of new issues of "Future Human Image".

\section{Cultural and Political Studies at the International Society of Philosophy and Cosmology}

Sergii Rudenko, Professor of Taras Shevchenko National University of Kyiv, coordinates this direction of the ISPC activities. Cultural and Political studies is a relatively young trend in the activities of the ISPC, which is a topical contradiction of the development of global civilization and corresponding local projections in the development of Ukrainian society. Future human must find themselves in a world that is not identical with the world in which previous generations lived. The academic study of the problems of Ukrainian society development, namely the substantiation of its political development opportunities, is directed by the activities of another ISPC magazine called "Ukrainian Policymaker" (http://www. ukrpolitic.com/).

The history of this publication has its roots in the large-scale political processes initiated by the Dignity Revolution in 2014, which have significant social and research demand. ISPC members and foreign authors, feeling the responsibility of educators and representatives of other humanities and social studies, join the journal issue twice a year, which became the subject of futurological forecasts for the development of Ukraine after 2014, analysis of education opportunities in peacekeeping, evaluation of prospects for the implementation of 
various geopolitical vectors, etc. This ethos of responsibility resonates with the urgent needs asserted 25 years ago to reinvigorate the role of intellectuals in solving global problems that would be the driving force behind the New Enlightenment (Ralph Darendorf et al.).

It is clear that the implementation of the above projects does not exhaust the scientific and educational activities of the International Society of Philosophy and Cosmology, which continues to seek answers to the most pressing today's problems for the common future of humanity. Therefore, in 2018, with the support of the ISPC, the International Round Table "Leaving Totalitarianism Behind: Cultural Practices in Central and Eastern Europe" was held. Among the co-organizers of the event were also the Faculty of Philosophy of Taras Shevchenko National University, the Faculty of Humanities of Zelenogorsk University (Poland), as well as the Department of Philosophy of the National University of National Studies named after V. Lazaryan. The implementation of this and other projects within the framework of Cultural and Political studies resonates with the need to find effective security strategies in both the specific socio-cultural situation of Ukraine and the global dimension. Peacebuilding and the justification of security strategies, based on the analysis of the publications of the ISPC members, are the subject of their research, resonating with current challenges.

In the framework of the development of external cooperation in the field of political studies, in 2018, a principled agreement was reached with the Faculty of Political Science and International Relations of Matej Bel University (Slovakia) on the implementation of academic cooperation. The agreement will allow scientists from Ukraine and Slovakia to undertake joint scientific research to solve pressing scientific problems, to publish articles in journals published by the ISPC, and to practice other forms of academic partnership.

Members of the ISPC and its leadership pay special attention to the possibility of developing scientific and cultural cooperation with leading Chinese scientific schools and institutions. As part of the Eastern Cooperation Vector, in 2019, the ISPC delegation visited one of China's most developed and innovative provinces, Guangdong, and intensified cooperation with one of the leading universities in the region, the Guangdong University of Petrochemical Technologies (Maoming, China). This powerful university, after lengthy preliminary talks and academic discussions, has recognized the potential of the ISPC to engage in prospective research on China-Europe relations, to substantiate strategies for implementing the "One Belt, One Way" initiative in the socio-cultural space of Europe. It is the expertise in political studies, the considerable experience of the ISPC's research team and the focus on the sustainable and productive development of collaboration, which makes it possible to hope for a high efficiency of collaboration within the global scientific space

\section{Conclusions}

Thus, the activities of the International Society of Philosophy and Cosmology are relevant to the philosophical and cosmological discourse on an international scale. Meetings with eminent scientists, public figures and astronauts, organizing many international scientific conferences, publishing international scientific journals and collective monographs — all these are a natural result of the hard work of each member of this society within fifteen years of its operation.

The ultimate goal of this work is of national and global significance - the establishment of Ukraine as a cosmic state, as well as the conceptualization, promotion and practical implementation of the latest educational paradigm, which will be focused on education of human with the cosmic scale of perception of social and natural reality, but not limited to it. At the same time, the activities of the ISPC rather focus on a certain horizon - a conditional 
and unattainable line, the content of which for the members of this scientific community is directly updated under the influence of modern scientific discoveries and in response to the complex contradictions of the development of human civilization. The explication of the specific achievements of the scientific community, united within the framework of the ISPC, as well as the substantive evolution of a number of its initiatives, affirms the prospect of further implementation of projects towards integration into the global research space.

\section{DDd References}

Bazaluk, Oleg. Space Travels - Traveling Mentality. The course of lectures. Kyiv: KNT, 2012.

Bazaluk, Oleg. The Heroes of Ukraine on Education: Book 1. Kyiv: ISPC, 2014.

Bazaluk, Oleg, and Larysa Kharchenko. The Philosophy of the Cosmos as the New Universal Philosophical Teaching about Being. Philosophy and Cosmology, Volume 21, 2018: 6-13. https://doi.org/10.29202/phil-cosm/21/1

Cosmic Ukraine. Pereyaslav Region: almanac. Auth. project: O. Bazaluk, O. Shkyra, chief editor of Council L. Kadenyuk. Pereyaslav-Khmelnytskyi; Kyiv: TSUL, 2012.

Future Human Image: Whom and How should We Educate in the Rising Generations. Vol. 3. Edited by Oleg Bazaluk. Kyiv: ISPC, 2013.

Future Human Image: Whom and How should We Educate in the Rising Generations. Vol. 2. Edited by Oleg Bazaluk. Kyiv: Skif Publishing House, 2012.

Future Human Image: Whom and How should We Educate in the Rising Generations. Vol. 1. Edited by Oleg Bazaluk. Kyiv: Condor, 2011.

Space Travel: Science, Education, and Practice. Proceedings of the International Scientific Conference on Dec. 2, 2010. Kyiv: KUTEL, 2010. 